\title{
Bidirectional Influence of the COVID-19 Pandemic Lockdowns on Health Behaviors and Quality of Life among Chinese Adults
}

\author{
Xiuqiang Wang ${ }^{1,2}{ }^{\infty}$, Si Man Lei ${ }^{1,3}$, Shenglong Le ${ }^{1,4}$, Yanxiang Yang ${ }^{5}$, Boyi Zhang ${ }^{5}$, Wu Yao ${ }^{5}$, \\ Zan Gao ${ }^{6}(1)$ and Sulin Cheng ${ }^{1,2,4,5, *}$ \\ 1 Exercise Translational Medicine Center, Shanghai Center for Systems Biomedicine, \\ Shanghai Jiao Tong University, Shanghai 200240, China; wangxiuqiang@sjtu.edu.cn (X.W.); \\ alicelei@um.edu.mo (S.M.L.); longsonlok@sjtu.edu.cn (S.L.) \\ 2 Key Laboratory of Systems Biomedicine (Ministry of Education), Shanghai Center for Systems Biomedicine, \\ Shanghai Jiao Tong University, Shanghai 200240, China \\ 3 Faculty of Education, University of Macao, Macao, China \\ 4 Faculty of Sport and Health Sciences, University of Jyväskylä, 40014 Jyväskylä, Finland \\ 5 Exercise, Health and Technology Center, Department of Physical Education, Shanghai Jiao Tong University, \\ Shanghai 200240, China; yanxiang.yang@tum.de (Y.Y.); zbyboyee@gmail.com (B.Z.); \\ yaowu@sjtu.edu.cn (W.Y.) \\ 6 School of Kinesiology, University of Minnesota, Minneapolis, MN 55455, USA; gaoz@umn.edu \\ * Correspondence: shulin.cheng@jyu.fi; Tel.: +358-14-2602091
}

Received: 15 July 2020; Accepted: 30 July 2020; Published: 2 August 2020

\begin{abstract}
Background: The coronavirus disease 2019 (COVID-19) pandemic has created challenges that have caused profound changes in health behaviors. This study aimed to explore how COVID-19 is affecting the health-related quality of life (QoL) among Chinese adults. Methods: The data of health-related behaviors and QoL were collected via online surveys from 2289 adults (mean age $=27.8 \pm 12$ years) who had been isolated at home for an average of 77 days. Results: More than $50 \%$ of the respondents reported that their time engaged in daily physical activity (PA) decreased, while sedentary behavior (SB) time increased compared with that before the lockdown. Only $20 \%$ of the respondents reported engaging in moderate-to-vigorous PA, $23 \%$ of adults reported changed their diets to be healthier, and $30 \%$ reported consuming more vegetables, fruits, and milk products than before home-isolation. During home-isolation, $75.2 \%$ of the adults rated their sleep quality as very good, and $65 \%$ reported that they were satisfied with their QoL. Sleep quality mediated the relationship between PA and QoL. Conclusion: The two-to-three-month home-isolation has had mixed effects on adult health behaviors in China. The participants were found to have focused more on their eating quality and patterns, which had a positive influence on their QoL. However, people should be encouraged to exercise at home with limited space to maintain a generally healthy lifestyle during a prolonged quarantine.
\end{abstract}

Keywords: diet; pandemic; physical activity; sedentary behavior; sleep

\section{Introduction}

Since its outbreak in China in December 2019, coronavirus disease 2019 (COVID-19) has infected more than 10.08 million people and has resulted in at least 483,000 deaths worldwide [1]. The pandemic, declared as a global public health emergency by the World Health Organization (WHO) [2], has led many governments and public health agencies to take drastic mitigation measures, including community-wide 
lockdowns, home quarantines, working-from-home, social distancing, and the prohibition of social gatherings, to stop the spread of COVID-19 and reduce the risk of human-to-human transmission.

The rapid spread of the novel coronavirus along with swift actions taken in response to the COVID-19 pandemic has created a host of new challenges that have brought profound changes and have affected the normal routines of health behaviors and lifestyles for people of all ages, such as restricting outdoor or free-living physical activity (PA), increasing sedentary time, disrupting sleep, and, consequently, adversely affecting the health-related quality of life (QoL) during a nonpandemic era [3]. A recent study showed that the COVID-19 pandemic has negatively affected the mental health (e.g., stress and depression) and QoL among Chinese adults [4]. Before the COVID-19 pandemic, most Chinese people, particularly young adults and those living in large cities, were under various pressures regarding their daily life, such as work-related competition, housing, and daily travel from home to the workplace [5]. However, empirical evidence concerning changes in PA, sedentary behavior, sleep, diet, and QoL as a result of the pandemic remains largely unexplored. The present study was designed to describe the patterns of Chinese adult PA, sedentary behavior, sleep, diet, and QoL under the COVID-19 pandemic, as well as the impact of the pandemic on their lifestyle behaviors and QoL compared with those outcomes before the pandemic.

Previous studies have suggested that PA and diet are critical components of healthy lifestyle behaviors, linking not only sleep quality but also the QoL [6-10]. Evidence has also indicated the critical role of sleep quality in mediating the effect of PA and/or diet on maintaining good health [11-13]. Gothe et al. proposed that a novel sleep and QoL model is useful to design new health interventions by targeting PA to promote sleep quality, which, in turn, influences the QoL [14]. However, given the massive impact of COVID-19 on all aspects of society, little understanding exists about how adult healthy behaviors, sleep, and the health-related QoL are related under the extremely restricted conditions in different regions of China. On the one hand, decreases in PA and increases in sedentary behavior (SB) could have negative impacts on the health-related QoL, sleep quality could mediate the relationships between healthy lifestyle behaviors (PA and food consumption) and QoL, and a bidirectional relationship may exist between these lifestyle factors and psychological health [15]. On the other hand, staying at home may also exert a positive influence on individuals' eating behaviors while they stay with all family members and care more about their eating quality, in addition to being more relaxed from their daily busy work schedule. Thus, it is urgent to investigate whether sleep mediates the relationships among PA, diet, and QoL in Chinese adults during the pandemic.

Based on previous studies, we hypothesized the following: (1) Chinese adult PA would decrease while SB would increase, and dietary intake would become healthier during the pandemic, (2) the impact of the COVID-19 pandemic on human lifestyle behaviors and QoL would be mixed due to Chinese culture, and (3) sleep would mediate the relationships among PA, diet, and QoL in Chinese adults. Therefore, this study aimed to explore how COVID-19 is affecting the health-related QoL among Chinese adults. Specifically, we aimed to: (1) describe the patterns of Chinese adult PA, SB, food consumption, sleep, and QoL during the high peak of the lockdown from February to April 2020, (2) assess how healthy behaviors have been changed compared with those before the lockdowns, and (3) investigate the associations of $\mathrm{PA}, \mathrm{SB}$, and food consumption with each domain of the QoL (physical, social, psychological, and environmental domains) and the overall QoL, as well as whether those relationships were mediated by sleep quality during the lockdown. This study may provide useful and timely information to develop new action plans for physical education and public health services if another outbreak occurs (e.g., the Beijing COVID-19 outbreak in June 2020), as well as how to adopt a future "new normal" after the COVID-19 pandemic. 


\section{Methods}

\subsection{Study Design and Participants}

\subsubsection{Participants}

The study utilized a cross-sectional design with a convenience sample. The inclusion criteria were participants who: (1) were aged older than 18 years, (2) could read and understand the Chinese language and the purpose of the survey, and (3) had no diagnosed physical or mental disability. Eligible participants were asked about their physical and mental conditions before and during the COVID-19 isolation. The duration of the home isolation was, on average, 78 days (56-95 days), and the survey period ranged from 23 March to 26 April 2020. Originally, we anticipated obtaining 3000 samples for this survey. Finally, we successfully recruited 2289 participants from 34 provinces across China, yielding a response rate of $76.3 \%$.

\subsubsection{Study Design}

We collected data on PA, SB, food consumption, sleep quality, and QoL from Chinese adults through commercial online survey platforms (i.e., WenJuanXing and WeChat). First, the participants' demographic and socioeconomic information was collected (i.e., education, occupation, and physical and mental conditions). Additionally, the survey inquired about lifestyle behaviors, such as the levels of PA, SB, food consumption, smoking, drinking, sleep quality, and QoL. The internal reliability of the questionnaires was assessed using a confirmatory factor analysis.

The study was performed in accordance with the Declaration of Helsinki and was approved by the local ethics committee of the Exercise, Health and Technology Centre, Department of Physical Education at Shanghai Jiao Tong University, China (ML2019052). Informed consent was obtained from each participant before the beginning of the survey. The participants were volunteers without a monetary incentive, and they were informed about the use of their information.

\subsection{Measurements}

\subsubsection{Physical Activity}

The PA level was assessed using the modified International Physical Activity Questionnaire Short Form (IPAQ-SF, Chinese version, which was translated by Qu [16]) [17]. The IPAQ-SF required participants to recall their PA engagement within the last seven days. The items were modified relative to prior to and during COVID-19 isolation (i.e., what is your vigorous PA level during the COVID-19 pandemic?) and activity types including typical traditional Chinese exercise; for example, "what was the frequency and duration spent on moderate PA (e.g., jogging, Tai Chi, and dancing) and low PA (e.g., yoga, Chinese traditional stretch exercise, and Baduanjin)" The guidelines for data processing and the analysis of the IPAQ-SF were followed [18]. The SB indicated the sitting and lying down hours spent on activities such as using a phone or computer or watching TV. The Cronbach's alpha of the IPAQ-SF was 0.76. The IPAQ-SF has also shown acceptable measurement properties with Chinese populations [19].

\subsubsection{Food Consumption}

The questionnaire for food consumption was adopted from the online nutritional survey of Guangdong Nutrition Society and Sun Yat-sen University with permission [20]. The consumption of different foodstuffs was collected during the isolation, and it was compared with that before isolation and included the weekly frequency and the total amount of consumption of whole grain products (e.g., rice, steamed buns, and steamed stuffed buns), meat products (e.g., pork, beef, fish, poultry, and eggs), dairy products (e.g., milk and yogurt), vegetables and fruits, snacks, alcohol, water, and soft drinks. The Cronbach's alpha of the instrument in this questionnaire was 0.68 in this study. 


\subsubsection{Sleep}

Sleep quality was assessed using the Pittsburgh Sleep Quality Index (PSQI) [21]. The PSQI is a 20-item scale with seven domains: sleep quality, sleep duration, sleep latency, habitual sleep efficiency, sleep disturbances, sleep drug use, and daytime impairments. However, in this study, we did not include sleep disturbances; therefore, the total score calculation only included 6 items. Each domain was scored from 0 to 3, and a summed global score was calculated (ranging from 0 to 18). A higher PSQI global score indicates a lower sleep quality [22]. The Cronbach's alpha of the PSQI was 0.82 in this study.

\subsubsection{Quality of Life}

The World Health Organization Quality of Life (QoL) questionnaire (WHOQOL-BREF) [23] was used to assess the QoL. The WHOQOL-BREF contains four domains: psychological health (6 items), physical health ( 7 items), social relations ( 3 items), and environment-related domain ( 8 items). Additionally, two extra items were related to the overall perception of the QoL (Q1) and perceived health satisfaction $(\mathrm{Q} 2)$. The items were scored on a $1-5$ Likert scale $(1=$ strongly disagree; $5=$ strongly agree). A global score was summed according to the domains, with higher scores reflecting a higher QoL. We obtained permission to use the English/Chinese version of the WHOQOL-BREF, and its Cronbach's alpha in the current study was 0.89 .

\subsection{Statistical Analyses}

Continuous data were checked for normality using the Shapiro-Wilk's W-test with IBM SPSS Statistics 24.0 for Windows (SPSS, Inc., Chicago, IL, USA). If these continuous data were not normally distributed, their natural logarithms were used for further analysis. For objective 1, descriptive statistics were used to present the data means and standard deviation (SD). For objective 2, a cross-table Chi-squared $\left(\chi_{2}\right)$ analysis was used to assess the changes compared with those before the lockdown, and the results are presented as numbers $(n)$ and proportions (\%). Additionally, we compared differences between gender, occupation, education, and living regions in health behaviors and QoL by independent $t$ tests and analyses of variance.

Next, we used structural equation modeling (SEM) to test the third objective using Analysis of Moment Structure v25.0 [24]. A two-step process was involved. First, confirmatory factor analyses were conducted for the measurement model. The second step focused on testing all hypothesized relationships in the structural model (Figure 1). We used maximum likelihood estimation to evaluate the fit of the structural model to the data. Second, the criteria to assess the structural model were the same as those of the measurement model, using path significance or standardized regression estimates. An acceptable model fit for both the measurement and structural models was assessed using multiple indices, as described below. Finally, an invariance test and a bootstrap mediation analysis were conducted to discern the effects of gender and students vs. other adult differences on the mediating relationships among the study variables. The criteria for a good SEM model fit were applied as follows [25]: (1) a $\chi_{2}$ /degree of freedom of less than 3; (2) a root mean square error of approximation (RMSEA) of less than 0.05; (3) a Tucker-Lewis index (TLI) and a comparative fit index (CFI), both greater than 0.90; and (4) a standardized root mean square residual (SRMR) of less than 0.05 . The level of significance was set at $p<0.05$ (two-tailed). 


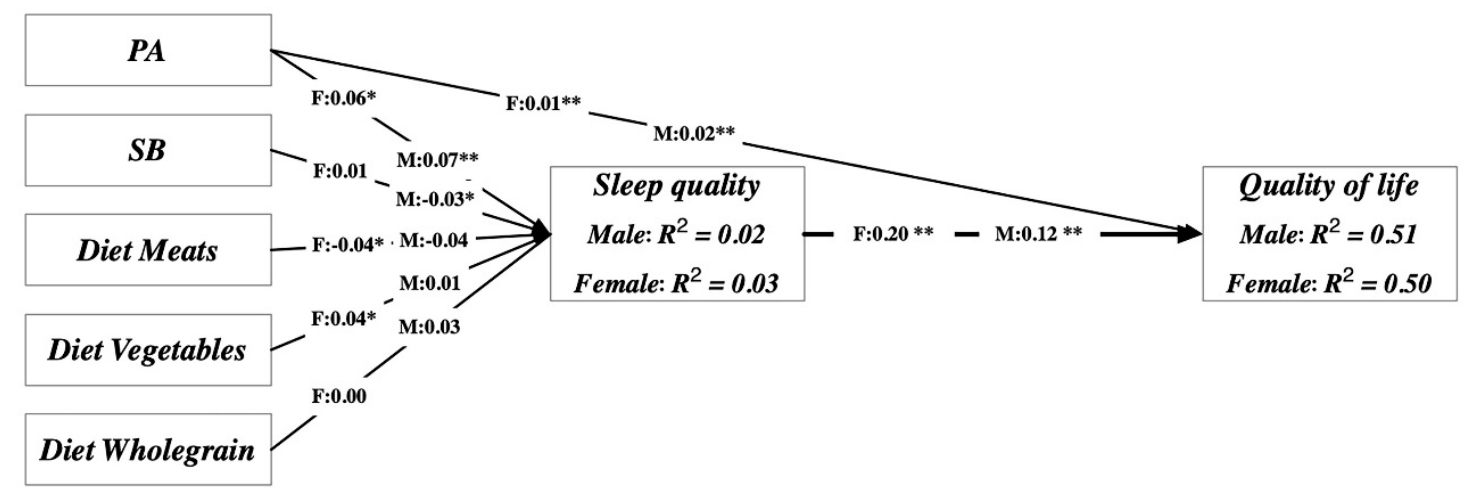

Figure 1. Scheme of path analysis. The model explained $50.9 \%\left(r_{2}=0.509\right)$ and $2.4 \%\left(r_{2}=0.024\right)$ of the variance in quality of life and sleep quality, respectively, in the male group and $49.6 \%\left(r_{2}=0.496\right)$ and $2.8 \%\left(r_{2}=0.028\right)$, respectively, in the female group.

\section{Results}

The demographic and descriptive characteristics of the participants are shown in Table 1. The sample comprised $1176(51.4 \%)$ men and 1113 (48.6\%) women aged 18-81 years (Table 1). Approximately $70 \%$ of the participants were aged 30 years or younger. Most of the participants were from Shanghai, followed by the East China region, and most reported a college degree or higher education level. Sixty-one percent of the participants were students, $28 \%$ were office workers (including teachers, doctors, nurses, business office workers, and secretaries), $7.5 \%$ were retired or unemployed, and only $3 \%$ were industrial workers, farmers, and other types of physical workers. Most of the participants were engaged in work that was lightly physically demanding. Ninety percent of the participants reported not having chronic diseases (e.g., hypertension, diabetes, cardiovascular disease, hyperlipidemia, and cancer) and were nonsmokers. The male participants ate more whole grain and meat products than the female participants. Approximately $30 \%$ of the male participants drank alcohol, while only $8 \%$ of the female participants did.

Table 1. Participant demographic and descriptive characteristics by gender.

\begin{tabular}{|c|c|c|c|c|}
\hline & $\begin{array}{c}\text { Total } \\
(\mathrm{N}=2289)\end{array}$ & $\begin{array}{c}\text { Male } \\
(\mathrm{N}=1176)\end{array}$ & $\begin{array}{c}\text { Female } \\
(\mathrm{N}=1113)\end{array}$ & $t$-Test \\
\hline & Mean (SD) & Mean (SD) & Mean (SD) & $p$-Value \\
\hline Age (yrs.) & $27.5 \pm 12.0$ & $26.8 \pm 11.9$ & $28.2 \pm 12.1$ & 0.008 \\
\hline Height $(\mathrm{cm})$ & $169.6 \pm 9.1$ & $176.1 \pm 6.6$ & $162.7 \pm 5.8$ & $<0.001$ \\
\hline Weight (kg) & $64.3 \pm 13.4$ & $71.7 \pm 12.7$ & $56.6 \pm 9.2$ & $<0.001$ \\
\hline Body Mass Index (BMI) $\left(\mathrm{kg} / \mathrm{m}^{2}\right)$ & $22.3 \pm 3.6$ & $23.1 \pm 3.6$ & $21.4 \pm 3.5$ & $<0.001$ \\
\hline Number (Proportion) & $n(\%)$ & $n(\%)$ & $n(\%)$ & $\begin{array}{c}\text { Chi-Squared } \\
p \text {-value }\end{array}$ \\
\hline Region & & & & 0.902 \\
\hline Shanghai & $676(29.5)$ & $352(29.9)$ & $324(29.1)$ & \\
\hline North China & $278(12)$ & $135(11.5)$ & $143(12.8)$ & \\
\hline South China & $491(21.5)$ & $253(21.5)$ & $238(21.4)$ & \\
\hline East China & $611(27.0)$ & 315 (26.8) & $296(26.6)$ & \\
\hline Macao, Hongkong, Taiwan & $233(10.0)$ & $121(10.3)$ & $112(10.1)$ & \\
\hline Vocation & & & & $<0.001$ \\
\hline Students & 1408 (62.0) & 769 (65.4) & 639 (57.4) & \\
\hline Others & $881(38.0)$ & $407(34.6)$ & $474(42.6)$ & \\
\hline Education & & & & 0.003 \\
\hline Under college & $251(11.0)$ & $109(9.3)$ & $142(3.8)$ & \\
\hline University & $1717(75.0)$ & $887(75.4)$ & $830(74.6)$ & \\
\hline Postgraduates and above & $321(14.0)$ & $180(15.3)$ & 141 (12.7) & \\
\hline
\end{tabular}


Table 1. Cont.

\begin{tabular}{|c|c|c|c|c|}
\hline & $\begin{array}{c}\text { Total } \\
(\mathrm{N}=2289)\end{array}$ & $\begin{array}{c}\text { Male } \\
(\mathrm{N}=1176)\end{array}$ & $\begin{array}{c}\text { Female } \\
(\mathrm{N}=1113)\end{array}$ & $t$-Test \\
\hline & Mean (SD) & Mean (SD) & Mean (SD) & $p$-Value \\
\hline Marital Status & & & & $<0.001$ \\
\hline Single & 1565 (68.0) & 849 (72.2) & $716(64.3)$ & \\
\hline Married & $682(30.0)$ & $313(26.6)$ & $369(33.2)$ & \\
\hline Divorced or widowed & $42(2.0)$ & $14(1.2)$ & $28(2.5)$ & \\
\hline Work physical demanding & & & & $<0.001$ \\
\hline Light physical activity & $1513(66.0)$ & $760(64.6)$ & 753 (67.7) & \\
\hline Moderate physical activity & $299(13.0)$ & $120(10.2)$ & $179(16.1)$ & \\
\hline Vigorous physical activity & $477(21.0)$ & $296(25.2)$ & $181(16.3)$ & \\
\hline Smoke & & & & $<0.001$ \\
\hline No & $2052(90.0)$ & $960(81.6)$ & $1092(98.1)$ & \\
\hline Yes & $180(8.0)$ & $171(14.5)$ & $9(0.8)$ & \\
\hline Quit & $57(2.0)$ & $45(3.8)$ & $12(1.1)$ & \\
\hline Drinking alcohol & & & & $<0.001$ \\
\hline No & $1811(79.0)$ & 794 (67.5) & 1017 (91.4) & \\
\hline Yes & $434(19.0)$ & 349 (29.7) & $85(7.6)$ & \\
\hline Quit & $44(2.0)$ & $33(2.8)$ & $11(1.0)$ & \\
\hline
\end{tabular}

\subsection{Descriptive Patterns of Chinese Adult PA, SB, Food Consumption, Sleep, and QoL}

The participants' PA behavior during the home-isolation period is presented in Figure 2 and Table 2. Most of the participants did not perform moderate-intensity PA (e.g., jogging, Tai Chi, and dancing; $40 \%$ ) and vigorous moderate-intensity PA (e.g., rope jumping and weight training; 55\%), and 18\% did not perform light-intensity PA (e.g., slow walking, yoga, and the Chinese traditional stretch exercise Baduanjin) (Figure 2A). The duration of exercise per time is presented in Figure 2B. Few people reported performing vigorous PA with a short duration. Additionally, we assessed daily PA (such as housework, lifting light and heavy loads, and carrying a baby) during the isolation period (Figure 2C,D). Approximately $10 \%$ of adults did not perform any light PA, and approximately $26 \%$ did not perform vigorous PA. In terms of SB, $20-42 \%$ of the participants reported an increase. No significant differences were found in the energy expenditures of daily exercise and daily PA between men and women (Table 2).

The participants' eating frequency and amount of food consumption are presented in Figure 3 and Table 2. Most of the adult food consumption fulfilled the recommendation of the dietary guidelines for Chinese residents (daily consumption of whole grain: 250-400 g; fish, poultry, meat, eggs, and other animal food sources: $120-200$ g; vegetables: $300-500$ g; fruits: $200-350 \mathrm{~g}$; milk products: $100 \mathrm{~g}$; and soy products: $50 \mathrm{~g}$ ). Compared with women, men reported more frequently consuming whole grains, meats, milk products, and eggs but less frequently consuming vegetables and fruits (Table 2; $p<0.01$ for all). Men also reported consuming higher amounts of whole grains, meat, milk products, and eggs. The overall amount of vegetables and fruits, did not differ between the genders.

Regarding sleep quality during home isolation, most of the participants rated their level of sleep quality as very good $(75.2 \%)$, approximately $21.1 \%$ rated it as fairly good, $3.4 \%$ rated it as fairly bad, and only $0.3 \%$ rated it as very bad. Men reported significantly higher sleep quality than women (Table 2).

During home isolation, $65.3 \%$ of participants were satisfied with their QoL. The mean summed global score of the QoL was 188.9 (Table 2). Among the four domains, the highest mean scores were for the environmental domain and social relationships, while the lowest mean scores were for the physical domain. Only the environmental domain showed a significant gender difference (Table 2). 


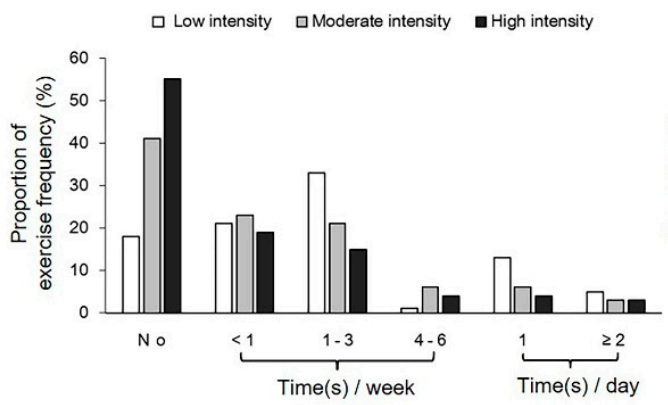

(A)

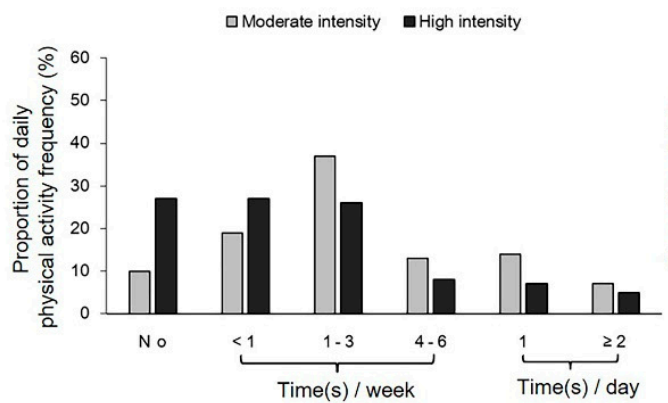

(C)

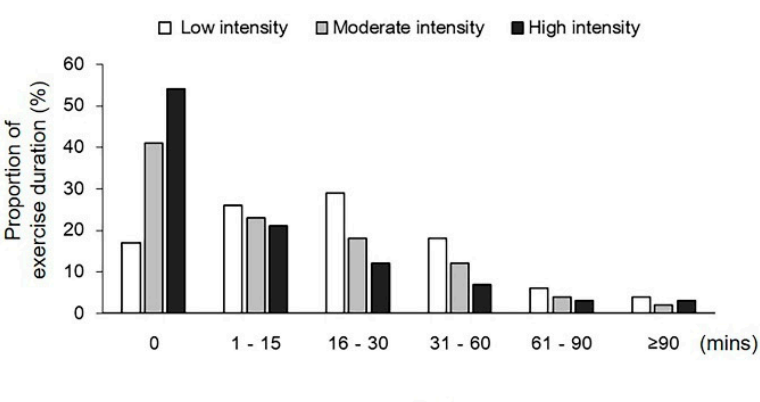

(B)

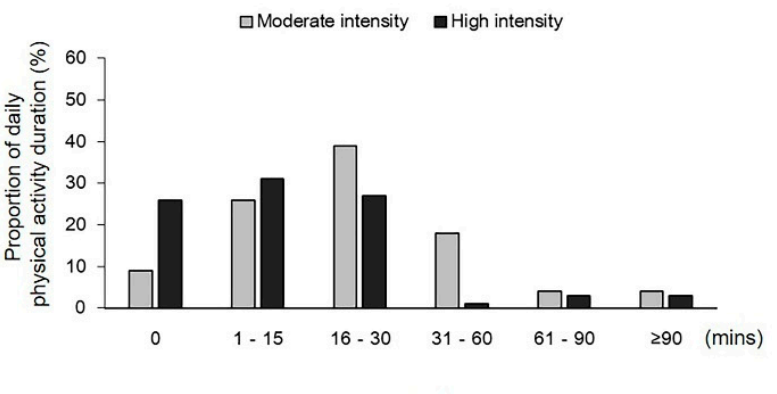

(D)

Figure 2. Proportion of people participating in physical activity (PA) during the home-isolation period. (A) Frequency of participation in different exercises. (B) Duration of participation in different exercises per time. (C) Frequency of participation in different daily physical activities. (D) Duration of participation in daily activities per time.

Table 2. Comparison of physical activity, food consumption, sleep, and quality of life between men and women.

\begin{tabular}{|c|c|c|c|c|}
\hline & $\begin{array}{c}\text { Total } \\
(\mathrm{N}=2289)\end{array}$ & $\begin{array}{c}\text { Male } \\
(\mathrm{N}=1176)\end{array}$ & $\begin{array}{c}\text { Female } \\
(N=1113)\end{array}$ & $t$-Test \\
\hline & Mean (SD) & Mean (SD) & Mean (SD) & $p$-Value \\
\hline \multicolumn{5}{|l|}{ SB (hours/day) } \\
\hline Sitting & $7.4 \pm 3.4$ & $7.5 \pm 3.3$ & $7.3 \pm 3.4$ & 0.135 \\
\hline Lying down & $9.2 \pm 3.7$ & $9.3 \pm 4.2$ & $9.1 \pm 3.0$ & 0.245 \\
\hline Exercise (Kcal/day) & $287.8 \pm 551.2$ & $299.8 \pm 607.6$ & $275.1 \pm 484.6$ & 0.284 \\
\hline Daily activity (Kcal/day) & $116.2 \pm 150.8$ & $110.4 \pm 151.4$ & $122.4 \pm 149.9$ & 0.057 \\
\hline \multicolumn{5}{|l|}{ Diets (g/day) } \\
\hline Whole grain & $246.1 \pm 244.5$ & $284.4 \pm 282.9$ & $205.5 \pm 187.5$ & $<0.001$ \\
\hline Meat products & $104.9 \pm 115.9$ & $120.8 \pm 133.1$ & $88.1 \pm 91.6$ & $<0.001$ \\
\hline Vegetables and Fruits & $131.6 \pm 93.5$ & $126.4 \pm 94.8$ & $137.1 \pm 91.9$ & 0.227 \\
\hline PSQI & $3.8 \pm 2.4$ & $3.6 \pm 2.4$ & $4.0 \pm 2.4$ & $<0.001$ \\
\hline Sleep quality & $0.96 \pm 0.6$ & $0.94 \pm 0.6$ & $0.98 \pm 0.6$ & 0.096 \\
\hline Sleep latency & $1.05 \pm 0.9$ & $0.98 \pm 0.9$ & $1.13 \pm 0.9$ & $<0.001$ \\
\hline Sleep duration & $0.32 \pm 0.6$ & $0.32 \pm 0.6$ & $0.31 \pm 0.6$ & 0.866 \\
\hline Habitual sleep efficiency & $0.48 \pm 0.9$ & $0.41 \pm 0.8$ & $0.56 \pm 0.9$ & $<0.001$ \\
\hline Use of sleep medications & $0.07 \pm 0.4$ & $0.08 \pm 0.4$ & $0.07 \pm 0.3$ & 0.341 \\
\hline Daytime impairments & $0.93 \pm 0.9$ & $0.88 \pm 0.9$ & $0.99 \pm 0.9$ & 0.002 \\
\hline \multicolumn{5}{|l|}{ QoL (score) } \\
\hline Overall perception of QoL & $3.6 \pm 0.9$ & $3.6 \pm 0.9$ & $3.6 \pm 0.9$ & 0.483 \\
\hline Satisfaction with health & $3.6 \pm 0.9$ & $3.7 \pm 0.9$ & $3.6 \pm 0.9$ & 0.067 \\
\hline
\end{tabular}


Table 2. Cont.

\begin{tabular}{ccccc}
\hline & $\begin{array}{c}\text { Total } \\
\mathbf{( N = \mathbf { 2 2 8 9 } )}\end{array}$ & $\begin{array}{c}\text { Male } \\
\mathbf{( N = \mathbf { 1 1 7 6 } )}\end{array}$ & $\begin{array}{c}\text { Female } \\
\mathbf{( N = 1 1 1 3 )}\end{array}$ & $\boldsymbol{t}$-Test \\
\cline { 2 - 5 } & Mean (SD) & Mean (SD) & Mean (SD) & $\boldsymbol{p}$-Value \\
\hline Physical & $54.6 \pm 13.2$ & $54.7 \pm 13.7$ & $54.5 \pm 12.7$ & 0.736 \\
Psychological & $57.2 \pm 13.9$ & $56.9 \pm 14.2$ & $57.5 \pm 13.6$ & 0.315 \\
Social relationships & $69.8 \pm 19.5$ & $70.2 \pm 20.6$ & $69.4 \pm 18.3$ & 0.315 \\
Environmental & $69.8 \pm 16.7$ & $70.5 \pm 17.0$ & $69.1 \pm 16.4$ & 0.038 \\
QoL (summed global score) & $188.9 \pm 40.4$ & $189.2 \pm 42.2$ & $188.6 \pm 38.4$ & 0.749 \\
\hline
\end{tabular}

Notes: Daily activity includes light activity (e.g., lifting light objects, cleaning, and scrubbing windows), vigorous daily activity (e.g., lifting heavy objects, dragging floors, and holding or carrying children). Whole grains include rice, steamed buns, steamed stuffed buns, noodles, and coarse grains. Meat products include pork, beef, fish, poultry, and eggs. Vegetables include leafy vegetables, wax gourds, tomatoes, and eggplant. Fruits include oranges, bananas, apples, cherries, strawberries, mangoes, peaches, pitayas, and pears. Abbreviations: $\mathrm{SB}=$ sedentary behavior; IPAQ = International Physical Activity Questionnaire Short Form; MET = metabolic equivalent; PSQI = Pittsburgh Sleep Quality Index; QoL = quality of life.

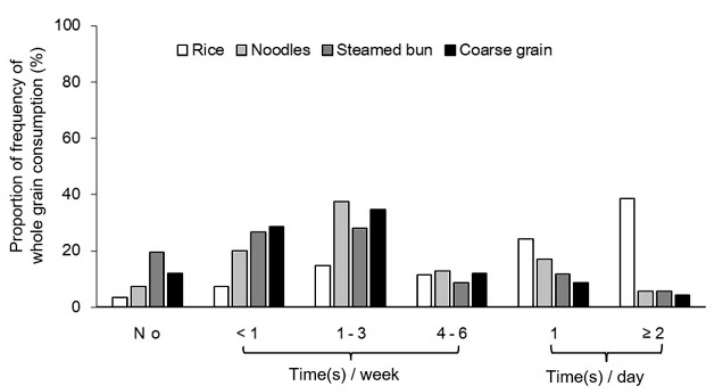

(A)

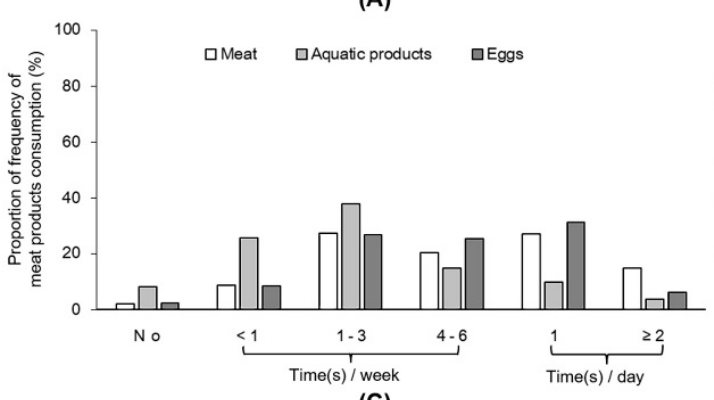

(C)

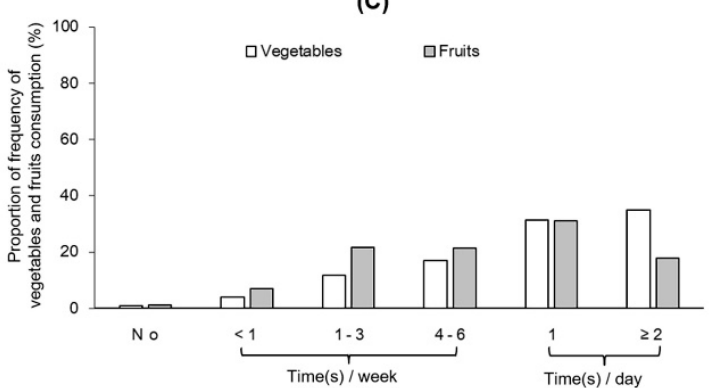

(E)

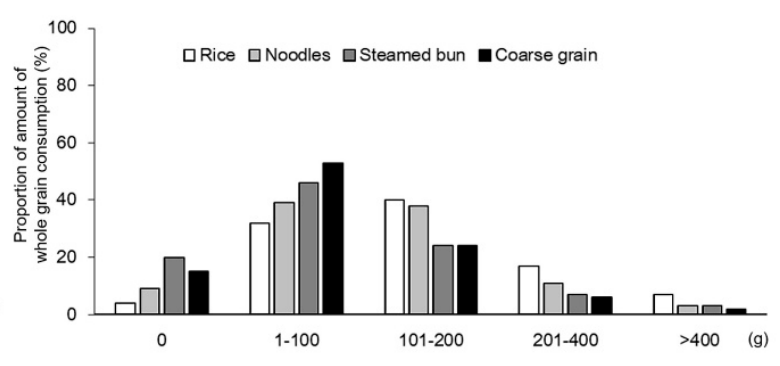

(B)

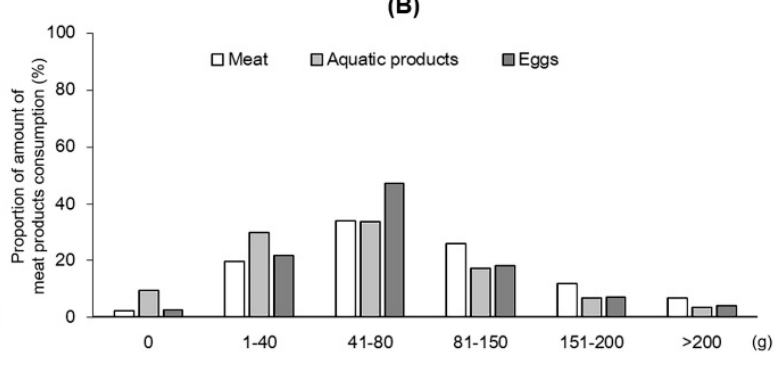

(D)

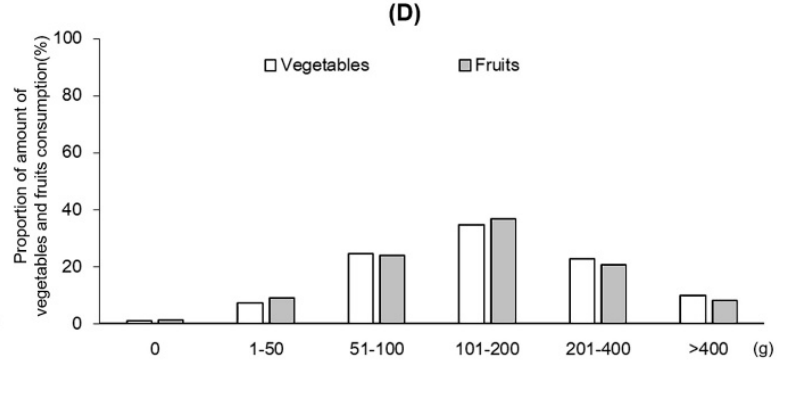

(F)

Figure 3. Proportion of dietary consumption frequency and daily amount during the home-isolation period. (A) Consumption frequency of whole grain. (B) Daily amount consumption of whole grain (C) Consumption frequency of meat products. (D) Daily amount consumption of meat products. (E) Consumption frequency of vegetable and fruit. (F) Daily amount consumption of vegetable and fruit.

\subsection{Change in Healthy Behaviors Compared with That before the Lockdown}

Most of the participants reported that their physical condition remained at the same level (82\%) as before home isolation, while approximately $9 \%$ of the participants reported their condition to be worse or better (Figure 4A). Fifty-two percent of the participants reported reduced levels of PA, while 17\% 
increased their amount of exercise, 44\% of the participants reduced their daily PA, and 19\% increased their daily PA (Figure 4B). In addition, $67 \%$ of the participants increased their sitting time, and $61 \%$ increased their time spent lying down (Figure 4B).

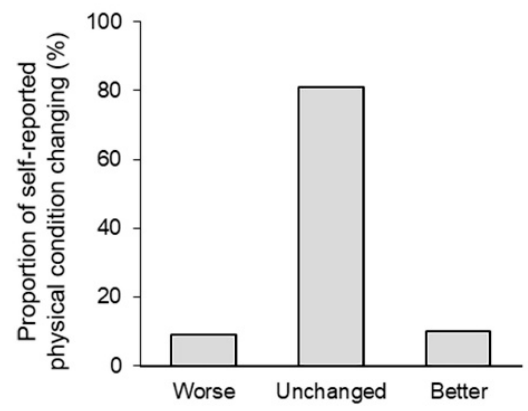

(A)

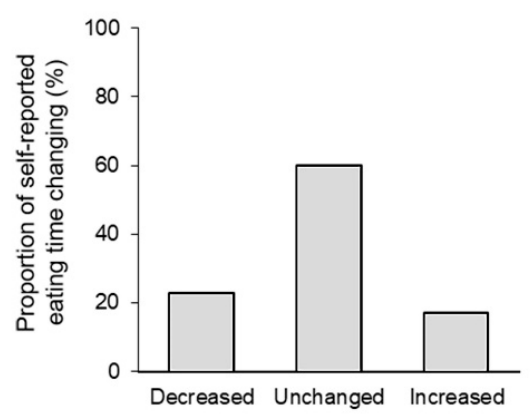

(C)

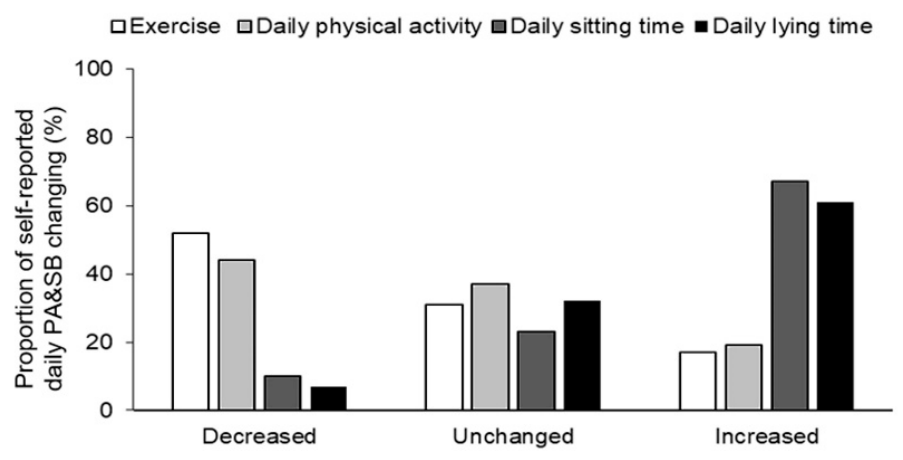

(B)

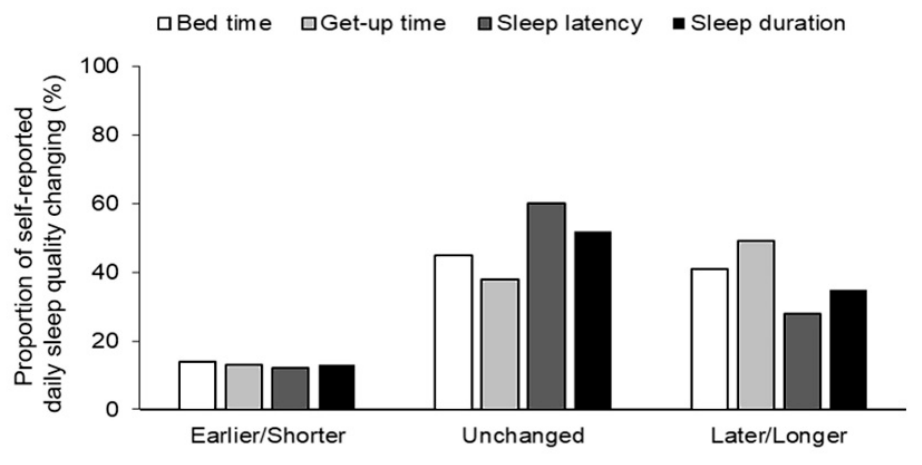

(D)

Figure 4. Proportion of self-perceived changes in physical condition and behaviors during the home-isolation period. (A) Change in physical condition. (B) Change in PA and sedentary behaviors. (C) Change in eating time. (D) Change in sleep quality.

Compared with their daily eating frequency before home isolation, $23.1 \%$ of the participants reduced their daily eating frequency, $17.3 \%$ increased their daily eating frequency, and $60 \%$ reported no changes during home isolation (Figure 4C). When asked whether they changed their appetite, $71.4 \%$ of the participants reported no changes. Notably, $23 \%$ changed their eating habits to be healthier. Regarding the different amounts of food consumption, more than $30 \%$ of participants consumed more vegetables, fruits, and milk products than before home isolation. Approximately $30 \%$ of participants reported an increased eating of snacks.

Forty-two percent of participants went to sleep late, and $49 \%$ woke up late in the morning compared with their sleeping behavior before isolation (Figure 4D). Approximately one-third of the participants reported longer times to fall asleep, and 35\% reported sleeping longer (Figure 4D). Twenty percent of the participants reported feeling less energetic, while $11 \%$ reported higher energy levels.

\subsection{Associations of PA, SB, and Food Consumption with QoL during the Lockdown}

Table 3 displays the correlations between the variables analyzed by Pearson's correlations $(r)$. Specifically, PA was positively correlated with the QoL and negatively associated with SB in all samples $(p<0.01)$. SB was negatively associated with the QoL in the overall sample $(r=-0.050$; $p<0.01)$. Additionally, the consumption of whole grains, meat products, and vegetables and fruits were correlated with the overall QoL score in men $(p<0.001)$. However, only the consumption of vegetables and fruits was correlated with the overall QoL score in women $(r=0.117 ; p<0.001)$ and was negatively with the physical domain $(r=-0.06 ; p=0.044)$. 
Table 3. Descriptive and correlational analyses among all outcome variables.

\begin{tabular}{|c|c|c|c|c|c|c|c|c|c|c|c|c|}
\hline \multirow{2}{*}{ Variable } & \multicolumn{4}{|c|}{ Total Sample $(\mathrm{N}=2289)$} & \multicolumn{4}{|c|}{ Men $(N=1176)$} & \multicolumn{4}{|c|}{ Women $(N=1113)$} \\
\hline & 1 & 2 & 3 & 4 & 1 & 2 & 3 & 4 & 1 & 2 & 3 & 4 \\
\hline \multicolumn{13}{|l|}{ 1. Physical activity } \\
\hline 2. Sedentary behavior (Sitting and lying down) & $-0.128 * *$ & & & & $-0.099 * *$ & & & & $-0.153 * *$ & & & \\
\hline 3. Sleep (PSQI) & 0.000 & 0.028 & & & -0.008 & 0.038 & & & 0.001 & 0.024 & & \\
\hline 4. Quality of Life & $0.212 * *$ & $-0.050 *$ & -0.023 & & $0.207^{* *}$ & -0.044 & -0.042 & & $0.219^{* *}$ & -0.058 & -0.001 & \\
\hline
\end{tabular}

Note. ${ }^{* *}$ Correlation is significant at the 0.01 level (2-tailed); ${ }^{*}$ Correlation is significant at the 0.05 level (2-tailed). Abbreviations: PSQI $=$ Pittsburgh Sleep Quality Index. 
The direct and indirect associations among the PA levels, SB, food consumptions, sleep quality, and QoL are presented in Table 4 . The criteria for the validity and reliability of the measurement model were largely fulfilled, with a total composite reliability of 0.92 (criterion $>0.70$ ) and an average variance extracted of 0.49 (criterion $>0.50$ ). The model had an acceptable model fit $\left(\chi_{2} / \mathrm{df}=780 / 288=2.7\right.$; $p<0.001 ; \mathrm{CFI}=0.87$; TLI $=0.93$; SRMR $=0.063$; and RMSEA $=0.045)$, as indicated by the criteria of $\chi_{2} / \mathrm{df}<3$; CFI $>0.90 ;$ TLI $>0.90 ;$ SRMR $<0.08$; and RMSEA $<0.05$, respectively. The model explained $50.9 \%\left(r_{2}=0.509\right)$ and $2.4 \%\left(r_{2}=0.024\right)$ of the variance in the QoL and sleep quality, respectively, in men and $49.6 \%\left(r_{2}=0.496\right)$ and $2.8 \%\left(r_{2}=0.028\right)$, respectively, in women. We found that PA was positively associated with the QoL in both men $(p<0.01)$ and women $(p<0.01)$. Furthermore, significant direct relationships were found between PA and sleep quality $(p<0.001)$ and between sleep quality and QoL $(p<0.001)$ in men. Similarly, the relationships were significant in women between PA and sleep quality $(p<0.01)$ and between sleep quality and QoL $(p<0.001)$. The mediation effect of sleep quality for the relationship between PA and QoL was significant for the total effects (i.e., sum of the direct and indirect effects: Path Coefficients $(\beta)=0.03$; Standard Error $(\mathrm{SE})=0.01 ; 95 \%$ Confidence Interval $(\mathrm{CI})=0.01-0.05 ;$ and $p<0.01)$.

Table 4. Direct and indirect associations between physical activity levels, sedentary behavior (SB), diet, sleep quality, and the quality of life (QoL).

\begin{tabular}{|c|c|c|c|c|c|c|}
\hline Path & Group & $\beta$ & SE & $p$-Value & CI.L & CI.U \\
\hline $\mathrm{PA} \rightarrow \mathrm{QoL}$ & \multirow{15}{*}{ Women } & 0.013 & 0.003 & $0.000^{* * *}$ & 0.006 & 0.020 \\
\hline Diet_wholegrain $\rightarrow$ QoL & & -0.002 & 0.004 & 0.630 & -0.009 & 0.006 \\
\hline Diet_meat $\rightarrow$ QoL & & 0.006 & 0.004 & 0.164 & -0.002 & 0.013 \\
\hline Diet_VegeFru $\rightarrow$ QoL & & 0.000 & 0.004 & 0.947 & -0.007 & 0.007 \\
\hline $\mathrm{SB} \rightarrow \mathrm{QoL}$ & & -0.002 & 0.004 & 0.575 & -0.009 & 0.005 \\
\hline Age $\rightarrow$ QoL & & 0.014 & 0.004 & $0.001 * *$ & 0.006 & 0.022 \\
\hline $\mathrm{BMI} \rightarrow \mathrm{Q} \mathrm{OL}$ & & -0.006 & 0.004 & 0.085 & -0.013 & 0.001 \\
\hline $\mathrm{PA} \rightarrow$ Sleep & & 0.046 & 0.013 & $0.000^{* * *}$ & 0.021 & 0.071 \\
\hline Diet_wholegrain $\rightarrow$ Sleep & & -0.025 & 0.017 & 0.153 & -0.059 & 0.009 \\
\hline Diet_meat $\rightarrow$ Sleep & & 0.005 & 0.018 & 0.804 & -0.031 & 0.040 \\
\hline Diet_VegeFru $\rightarrow$ Sleep & & 0.003 & 0.017 & 0.856 & -0.030 & 0.036 \\
\hline $\mathrm{SB} \rightarrow$ Sleep & & 0.002 & 0.016 & 0.926 & -0.030 & 0.033 \\
\hline Age $\rightarrow$ Sleep & & 0.013 & 0.016 & 0.413 & -0.019 & 0.045 \\
\hline $\mathrm{BMI} \rightarrow$ Sleep & & 0.023 & 0.016 & 0.143 & -0.008 & 0.055 \\
\hline Sleep $\rightarrow$ QoL & & 0.203 & 0.034 & $0.000^{* * *}$ & 0.136 & 0.269 \\
\hline $\mathrm{PA} \rightarrow \mathrm{QoL}$ & \multirow{15}{*}{ Men } & 0.014 & 0.005 & $0.003 * *$ & 0.005 & 0.024 \\
\hline Diet_wholegrain $\rightarrow$ QoL & & -0.003 & 0.003 & 0.212 & -0.009 & 0.002 \\
\hline Diet_meat $\rightarrow$ QoL & & 0.002 & 0.003 & 0.496 & -0.004 & 0.008 \\
\hline Diet_VegeFru $\rightarrow$ QoL & & 0.002 & 0.003 & 0.539 & -0.004 & 0.007 \\
\hline $\mathrm{SB} \rightarrow \mathrm{QoL}$ & & 0.001 & 0.002 & 0.570 & -0.003 & 0.006 \\
\hline Age $\rightarrow$ QoL & & 0.016 & 0.004 & $0.000^{* * *}$ & 0.007 & 0.024 \\
\hline $\mathrm{BMI} \rightarrow \hat{\mathrm{Q}} \mathrm{LL}$ & & 0.001 & 0.002 & 0.740 & -0.004 & 0.006 \\
\hline $\mathrm{PA} \rightarrow$ Sleep & & 0.073 & 0.024 & $0.003^{* *}$ & 0.025 & 0.121 \\
\hline Diet_wholegrain $\rightarrow$ Sleep & & 0.030 & 0.018 & 0.099 & -0.006 & 0.066 \\
\hline Diet_meat $\rightarrow$ Sleep & & -0.038 & 0.020 & 0.056 & -0.077 & 0.001 \\
\hline Diet_VegeFru $\rightarrow$ Sleep & & 0.009 & 0.018 & 0.631 & -0.027 & 0.044 \\
\hline $\mathrm{SB} \rightarrow$ Sleep & & -0.033 & 0.016 & $0.035 *$ & -0.064 & -0.002 \\
\hline Age $\rightarrow$ Sleep & & -0.018 & 0.017 & 0.265 & -0.051 & 0.014 \\
\hline $\mathrm{BMI} \rightarrow$ Sleep & & 0.016 & 0.017 & 0.363 & -0.018 & 0.049 \\
\hline Sleep $\rightarrow$ QoL & & 0.128 & 0.031 & $0.000^{* * *}$ & 0.068 & 0.188 \\
\hline $\mathrm{PA} \rightarrow$ Sleep $\rightarrow$ QoL & \multirow{8}{*}{ Mediation } & 0.009 & 0.003 & $0.002 * *$ & 0.003 & 0.015 \\
\hline Diet_wholegrain $\rightarrow$ Sleep $\rightarrow$ QoL & & -0.005 & 0.004 & 0.163 & -0.012 & 0.002 \\
\hline Diet_meat $\rightarrow$ Sleep $\rightarrow$ QoL & & 0.001 & 0.004 & 0.805 & -0.006 & 0.008 \\
\hline Diet_VegeFru $\rightarrow$ Sleep $\rightarrow$ QoL & & 0.001 & 0.003 & 0.856 & -0.006 & 0.007 \\
\hline $\mathrm{SB} \rightarrow$ Sleep $\rightarrow$ QoL & & 0.000 & 0.003 & 0.926 & -0.006 & 0.007 \\
\hline Age $\rightarrow$ Sleep $\rightarrow$ QoL & & 0.003 & 0.003 & 0.417 & -0.004 & 0.009 \\
\hline $\mathrm{BMI} \rightarrow$ Sleep $\rightarrow$ QoL & & 0.005 & 0.003 & 0.154 & -0.002 & 0.011 \\
\hline Total effects & & 0.028 & 0.010 & 0.003 & 0.010 & 0.047 \\
\hline
\end{tabular}

Abbreviations: $\mathrm{PA}=$ physical activity; $\mathrm{QoL}=$ quality of life; $\mathrm{SB}=$ sedentary behavior. $\beta$ : Path coefficients; SE: Standard Error; CI.L: Lower limit of $95 \%$ Confidence interval; CI.U: Upper limit of $95 \%$ Confidence interval; ${ }^{*} p<0.05,{ }^{* *} p<0.01,{ }^{* * *} p<0.001$. " $\mathrm{x} \rightarrow \mathrm{y}^{\text {" : }}$ path analysis examining the relationships between $\mathrm{y}$ (dependent variable) and $x$ (independent variable). 
However, SB showed no significant relationships with the QoL in both groups (men: $\beta=0.001$; $\mathrm{SE}=0.002$; and $p=0.57$; women: $\beta=-0.002$; $\mathrm{SE}=0.004$; and $p=0.58$ ). No significant mediation effect of sleep for SB and QoL was found ( $\beta=0.000$; $\mathrm{SE}=0.003 ; 95 \% \mathrm{CI}=-0.006-0.007$; and $p=0.93$ ). Additionally, no direct relationships were found in men between the QoL and meat products $(p>0.05)$, whole grains $(p>0.05)$, and vegetables and fruits $(p>0.05)$, nor were any found between sleep quality and meat products $(p>0.05)$, whole grains $(p>0.05)$, and vegetables $(p>0.05)$. Similarly, significant direct relationships were not identified in women between diet and QoL, nor between sleep and diet. Therefore, no significant mediation effects of sleep quality were observed on the relationships between the QoL and the consumption of meat products, whole grains, and vegetables and fruits (See Table 4).

\section{Discussion}

In this study, more than two-thousand participants from 34 provinces in China provided reports on their health behaviors and QoL during the two-to-three-month COVID-19 home isolation. Home isolation had the most influence on the Chinese adult participation in daily exercise and PA. As expected, confining people staying at their homes led to an increase in a physically inactive lifestyle. However, adults were more aware of their eating and changed toward a healthier eating pattern. The overall satisfaction with their QoL was reasonable; however, the physical and psychological domains of the QoL were relatively low, and the social and environmental domain scores were higher than those in a previous study [26].

We found that more than $50 \%$ of the participants reduced their PA time and over $60 \%$ increased their sedentary time. The reason for the reduced PA time may have partly been due to small living quarters in densely populated urban cities, limiting the capacity of individuals to engage in PA. In this study, more than half of the participants were from Shanghai and the East China region, which have populations of 3823 people per square kilometer [27] and a living area of 36.6 square meters per person [28]. The participants living in these areas reported more decreases in terms of moderate-to-vigorous PA. This result urges us to develop a new type of PA to adapt to such limited living conditions.

Another possible explanation for the reduction in PA is increased screen times during lockdown. The combination of a low PA and high screen-time demonstrated the greatest negative impact on the QoL [29]. More than $60 \%$ of the participants reported increased hours sitting and lying down to play with mobile phones and computers and watch TV. Empirical studies have shown that a sedentary lifestyle is associated with many chronic diseases [30], immunity [31], and increased mortality [31]. Particularly, individuals older than 50 years who sat for more than seven hours a day had four times increased mortality after controlling for various confounders (gender, age, race, education level, smoking and drinking, body composition, diabetes, cardiovascular disease, cancer, stroke, and osteoarthritis) [32]. Sitting for a long period not only affects physical health but also poses a serious threat to mental health [33]. Additionally, most people enjoy exercising outdoors, which tends to elevate the mood, release pressure, and they are more likely to continue exercising in the future [34]. The lockdown also limited and weakened individuals' exercise motivation because most of the venues and stadiums were closed and people were not familiar with workout routines for home training. Hence, the reduction in PA and increase in SB were mainly related to limited physical space and that people are not used to exercising at home during the COVID-19 pandemic in China.

Eating behaviors related to food choice and consumption are other important factors associated with sleep quality and QoL [35]. Before home isolation, most Chinese adults living in urban areas increased the frequency of eating outside due to the unwillingness to spend time in food preparation [32,36]. The 2011 "The Blue Book of the Catering Industry" annual report, a national survey comprising a population of 32,446 , reported that approximately $70 \%$ of the respondents liked to eat outside the home. In addition to working meals, $50 \%$ of the consumers ate out one-to-three times a week, those who ate out four-to-six times accounted for $26.47 \%$, and nearly $15 \%$ ate out every day [37]. The per capita food consumption increased from 5.7 Chinese yuan in 1980 to 2850 yuan in 2017, a 474-fold 
increase [38]. Eating outside has become routine in China due to improved living standards [38]. From the cultural perspective, although the proportion of Chinese eating in restaurants had risen sharply in recent years, most Chinese families still continue to the tradition of cooking their own meals at home because cooking is an important component of Chinese traditional culture. During home isolation, adults needed to cook and had time to make good decisions on food, and sharing meals with family also provided a positive impact through connection and communication [39]. Of note, there are numerous online shopping platforms in China. It was very convenient for people to buy fresh vegetables, fruits, and groceries online, even during the pandemic period. Meanwhile, China has a mature and developed logistics distribution system, so there was no real impact on individuals' online shopping during home isolation with the express delivery services. In the current study, approximately $40 \%$ of the participants had increased their consumption of fruits and vegetables, particularly women. The consumption of vegetables and fruits was positively correlated with sleep quality in women, indicating that women were more likely to pay attention to their eating quality to control their body weight [40]. Additionally, both men and women had increased their water consumption and reduced soft drinks. The influence of home isolation indicated that it might have a positive impact on adult behaviors. The improvement of Chinese people's eating habits during home-isolation is a novel finding of this study. It may shed light on individuals' eating behavior and foster healthy eating behavior for those in other countries. However, the participants were not asked about their motivations for these changes; thus, we cannot draw reliable conclusions on this matter.

Interestingly, we found that most of the participants maintained their sleep quality. About $40-50 \%$ of the participants reported going to sleep and waking up later than before the COVID-19 outbreak. Only approximately $12-14 \%$ of the participants reported more difficulty falling asleep and a reduced sleep quality. However, $10-16 \%$ of the participants reported improved sleep quality during home isolation. This was likely related to people changing their routine schedule. For the Chinese, staying at home or working or studying from home for two-to-three months was in some way similar to a "long holiday." Therefore, the COVID-19 outbreak afforded some people more time to relax to some extent. However, if home isolation is prolonged, the negative impact on individuals' physical and mental health may be inevitable when new strategies are not enforced [41].

Using SEM, we found that sleep had a direct effect on the QoL and served as the mediator in the model. PA significantly predicted sleep quality and indirectly affected the QoL via sleep quality. This finding agreed with the results of a previous study [42]. However, the mediation effects of sleep quality were not observed among diet, SB, and QoL, likely largely due to the home-restricted dietary pattern and SB [43]. Thus, the results of the SEM suggest that daily PA participation is imperative in promoting the QoL among Chinese adults, regardless of SB.

To promote and maintain health, the American College of Sports Medicine and the American Heart Association have recommended that "all healthy adults aged 18-65 years need moderate-intensity aerobic (endurance) PA for a minimum of $30 \mathrm{~min}$ on five days each week or vigorous-intensity aerobic PA for a minimum of $20 \mathrm{~min}$ on three days each week" [44]. Clearly, during home isolation, most people did not meet the recommendation. However, those who reported higher PA participation had a better perception of their QoL and sleep quality. This finding agrees with that in a previous study [42-46]. Therefore, a national PA guideline in house confinement should be established that is suited for individuals and families to promote healthy lifestyles during crises.

This study had several strengths and limitations. A major strength of the study was the inclusion of a large sample of Chinese adults from many regions under the COVID-19 crisis to study their health behaviors and QoL through advanced statistical techniques. The present study data from questionnaires that have relatively good reliability and validity. However, the participants were mostly from Shanghai, and approximately $60 \%$ of them were college students, a finding that may have induced a bias of population representation in China. The SEM was based on previous knowledge to assess the direct and indirect associations among PA, SB, sleep, and QoL. Missing information, such as home living conditions and household members, may have played a role in explaining the outcomes. 
Additionally, $23 \%$ of the participants had already returned to work or study when the questionnaire was completed, a situation that may have affected their perceptions of health behaviors. Finally, due to the observational study design, cause-effect relationships among the study variables in this study could not be determined. A future study should adopt a longitudinal cohort design to explore the lifestyle health behaviors and QoL of Chinese adults.

To our best knowledge, this is the first study to investigate the status of PA, SB, diet, sleep, and QoL, as well as the associations among them, within a large Chinese adult sample during a global public health crisis. The conclusions drawn by this study contribute to the growing literature pool regarding PA promotion in a developing country population under unusual circumstances. COVID-19 is a new emerging situation that has dramatically impacted both individuals and their society. Our findings may provide useful and timely information in developing new action plans for physical education and public health services. In detail, the results may help inform healthcare professionals, practitioners, and educators on the status of Chinese adult lifestyle behaviors and health, in addition to offering innovative and effective PA programs at home during challenging circumstances such as a pandemic or heavy smog days. In future PA trials, it is necessary to use a randomized controlled design to examine the effectiveness of enjoyable and novel PA at-home programs given that most Chinese adults reported decreased PA during lockdown. Future home-based PA interventions could potentially focus on developing and maintaining physically active lifestyles for men and women alike. Finally, there is a need to investigate the effects of PA, SB, and sleep on cognitive functions [45] and mental health in adults in the future.

\section{Conclusions}

Our results indicate that the two-to-three-month home isolation during COVID-19 had mixed influences on Chinese adult health behaviors. Additionally, PA participation during containment measures was associated with better QoL and sleep quality levels, and sleep quality also served as the mediator in the model. People ate at home and focused more on their eating quality and patterns, which had positive influences on the QoL, particularly in women. However, the substantially reduced amount of moderate-to-vigorous PA warrants the identification of ways to enable and encourage people to engage in PA at home with limited space. Both government and communities should recommend practical guidance for adults to participate in PA with moderate-to-vigorous intensity that can be easily adopted at home, thus helping to maintain a healthy lifestyle in general and during a prolonged quarantine.

Author Contributions: X.W., S.M.L., and S.C. designed the survey and participated in data collection, data analysis and drafting of the manuscript. S.L., Y.Y., B.Z. and W.Y. participated in data collection, data analysis and editing of the manuscript. Z.G. participated in data analysis and editing of the manuscript. All the authors had final approval of the submitted version. X.W. and S.C. had full access to all of the data in the study and take responsibility for the integrity of the data and accuracy of the data analysis. All authors have read and agreed to the published version of the manuscript.

Funding: The study was funded by the start-up plan for new young teachers grant (Grant AF4150043) and Zhiyuan Foundation (Grant CP2014013) from Shanghai Jiao Tong University, China.

Acknowledgments: We would like to thank for Huilian Zhu from Sun Yat-sen University and Guangdong Nutrition Society for her generosity of providing their online nutritional survey and for participants for their contribution to the study.

Conflicts of Interest: The authors declare no conflict of interest.

\section{Abbreviations}

The following abbreviations are used in this manuscript.

$\begin{array}{ll}\text { COVID-19 } & \text { Coronavirus Disease } 2019 \\ \text { PA } & \text { Physical Activity } \\ \text { QoL } & \text { Quality of Life } \\ \text { SB } & \text { Sedentary Behavior }\end{array}$




$\begin{array}{ll}\text { IPAQ-SF } & \text { International Physical Activity Questionnaire Short Form } \\ \text { PSQI } & \text { Pittsburgh Sleep Quality Index } \\ \text { WHOQOL-BREF } & \text { World Health Organization on Quality of Life Brief Scale } \\ \text { SD } & \text { Standard Deviation } \\ \chi_{2} & \text { Cross-table Chi-squared } \\ \text { SEM } & \text { Structural Equation Modeling } \\ \text { RMSEA } & \text { Root Mean Square Error of Approximation } \\ \text { TLI } & \text { Tucker-Lewis Index } \\ \text { CFI } & \text { Comparative Fit Index } \\ \text { SRMR } & \text { Standardized Root Mean Square Residual } \\ \text { MET } & \text { Metabolic Equivalent } \\ \beta & \text { Path Coefficients } \\ \text { SE } & \text { Standard Error } \\ \text { CI.L } & \text { Lower Limit of 95\% Confidence Interval } \\ \text { CI.U } & \text { Upper Limit of 95\% Confidence Interval } \\ * & p<0.05 \\ * * & p<0.01 \\ * * * & p<0.001 \\ \text { “x } \rightarrow y \text { " } & \text { Path Analysis Examining the Relationships between y (dependent } \\ & \text { variable) and x (independent variable) }\end{array}$

\section{References}

1. Johns Hopkins University. Coronavirus COVID-19 Global Cases by the Center for Systems Science and Engineering (CSSE) at Johns Hopkins University. Available online: https://www.arcgis.com/apps/ opsdashboard/index.html\#/bda7594740fd40299423467b48e9ecf6 (accessed on 21 June 2020).

2. World Health Organization. Statement on the Second Meeting of the International Health Regulations (2005) Emergency Committee Regarding the outbreak of Novel Coronavirus (2019-nCoV). Available online: https://www.who.int/news-room/detail/30-01-2020-statement-on-the-second-meeting-of-the-internationalhealth-regulations-(2005)-emergency-committee-regarding-the-outbreak-of-novel-coronavirus-(2019-ncov) (accessed on 30 January 2020).

3. Shanghai Municipal People's Government. Shanghai Municipal People's Government on the Further Strict Implementation of the Epidemic Prevention and Control Measures Circular. Available online: http: //www.shanghai.gov.cn/nw2/nw2314/nw2319/nw12344/u26aw63661.html (accessed on 10 February 2020).

4. Zhang, Y.; Ma, Z.F. Impact of the COVID-19 pandemic on mental health and quality of life among local residents in Liaoning Province, China: A cross-sectional study. Int. J. Environ. Res. Public Health 2020, 17, 2381. [CrossRef] [PubMed]

5. CBN weekly, Omron Health. Urban Stress Survey Report Shanghai. Available online: http://www.cnr.cn/ shanghai/tt/20180610/t20180610_524264808.shtml. (accessed on 10 June 2018).

6. Tao, K.; Liu, W.; Xiong, S.; Ken, L.; Zeng, N.; Peng, Q.; Yan, X.; Wang, J.; Wu, Y.; Lei, M.; et al. Associations between self-determined motivation, accelerometer-determined physical activity, and quality of life in Chinese college students. Int. J. Environ. Res. Public Health 2019, 16, 2941. [CrossRef] [PubMed]

7. Zeng, N.; Tao, K.; Peng, Q.; Xiong, S.; Li, X.; Gao, Z. Examining the relationships between physical activity participation and sleep quality in Chinese college students. Med. Sci. Sports Exerc. 2018, 50, 701. [CrossRef]

8. Guallar-Castillon, P.; Bayan-Bravo, A.; Leon-Munoz, L.M.; Balboa-Castillo, T.; Lopez-Garcia, E.; Gutierrez-Fisac, J.L.; Rodriguez-Artalejo, F. The association of major patterns of physical activity, sedentary behavior and sleep with health-related quality of life: A cohort study. Prev. Med. 2014, 67, 248-254. [CrossRef] [PubMed]

9. McClain, J.J.; Lewin, D.S.; Laposky, A.D.; Kahle, L.; Berrigan, D. Associations between physical activity, sedentary time, sleep duration and daytime sleepiness in US adults. Prev. Med. 2014, 66, 68-73. [CrossRef]

10. Saleh, D.; Janssen, I. Interrelationships among sedentary time, sleep duration, and the metabolic syndrome in adults. BMC Public Health 2014, 14, 666. [CrossRef]

11. Chaput, J.P.; Dutil, C. Lack of sleep as a contributor to obesity in adolescents: Impacts on eating and activity behaviors. Int. J. Behav. Nutr. Phys. Act. 2016, 13, 103. [CrossRef] 
12. Kaar, J.L.; Schmiege, S.J.; Vadiveloo, M.; Simon, S.L.; Tovar, A. Sleep duration mediates the relationship between health behavior patterns and obesity. Sleep Health 2018, 4, 442-447. [CrossRef]

13. Kaar, J.L.; Luberto, C.M.; Campbell, K.A.; Huffman, J.C. Sleep, health behaviors, and behavioral interventions: Reducing the risk of cardiovascular disease in adults. World J. Cardiol. 2017, 9, 396-406. [CrossRef]

14. Gothe, N.P.; Ehlers, D.K.; Salerno, E.A.; Fanning, J.; Kramer, A.F.; McAuley, E. Physical activity, sleep and quality of life in older adults: Influence of physical, mental and social well-being. Behav. Sleep Med. 2019, 1-12. [CrossRef]

15. Lopresti, A.L.; Hood, S.D.; Drummond, P.D. A review of lifestyle factors that contribute to important pathways associated with major depression: Diet, sleep and exercise. J. Affect. Disord. 2013, 148, 12-27. [CrossRef] [PubMed]

16. Qu, N.N.; Li, K.J. Reliability and validity of the Chinese version of the international physical activity questionnaire. China J Epidemiol. 2004, 25(3), 265-268.

17. Lee, P.H.; Macfarlane, D.J.; Lam, T.H.; Stewart, S.M. Validity of the international physical activity questionnaire short form (IPAQ-SF): A systematic review. Int. J. Behav. Nutr. Phys. Act. 2011, 8, 115. [CrossRef] [PubMed]

18. Hallal, P.C.; Andersen, L.B.; Bull, F.C.; Guthold, R.; Haskell, W.; Ekelund, U.; Lancet Physical Activity Series Working Group. Global physical activity levels: Surveillance progress, pitfalls, and prospects. Lancet 2012, 380, 247-257. [CrossRef]

19. Macfarlane, D.J.; Lee, C.C.Y.; Flo, E.Y.; Chan, K.L.; Chan, D.T.S. Reliability and validity of the Chinese version of IPAQ (short, last 7 days). J. Sci. Med. Sport 2007, 10, 45-51. [CrossRef]

20. Guangdong Nutrition Society \& Department of Nutrition, Sun Yat-Sen University. A Questionnaire on the Nutritional Status of Populations During COVID-19. Available online: https://www.wjx.cn/m/59273857. aspx (accessed on 3 March 2020).

21. Buysse, D.J.; Reynolds, C.F.; Monk, T.H.; Berman, S.R.; Kupfer, D.J. The Pittsburgh sleep quality index: A new instrument for psychiatric practice and research. Psychiatry Res. 1989, 28, 193-213. [CrossRef]

22. Hartmann, J.A.; Wichers, M.; Van Bemmel, A.L.; Derom, C.; Thiery, E.; Jacobs, N.; Van Os, J.; Simons, C.J.P. The serotonin transporter 5-HTTLPR polymorphism in the association between sleep quality and affect. Eur. Neuropsychopharmacol. 2014, 24, 1086-1090. [CrossRef]

23. Harper, A.; Power, M.; Grp, W. Development of the World Health Organization WHOQOL-BREF quality of life assessment. Psychol. Med. 1998, 28, 551-558.

24. Arbuckle, J.L. Amos 5.0 Update to the Amos User's Guide; SmallWaters Corporation: Chicago, IL, USA, 2003.

25. Weston, R.; Gore, P.A. A brief guide to structural equation modeling. Couns. Psychol. 2006, 34, 719-751. [CrossRef]

26. Xia, P.; Li, N.; Hau, K.-T.; Liu, C.; Lu, Y. Quality of life of Chinese urban community residents: A psychometric study of the mainland Chinese version of the WHOQOL-BREF. BMC Med. Res. Methodol. 2012, 12, 37. [CrossRef]

27. Shanghai Bureau of Statistics. Shanghai Statistical Yearbook. Available online: http://jj.sh.gov.cn/tjnj/ 20200427/4aa08fba106d45fda6cb39817d961c98.html (accessed on 5 May 2020).

28. Sun, C.; Liu, X.; Yao, L. How does housing supply satisfy the differentiated demand of tenants and homebuyers in the new era? evidence from shanghai. Int. J. Financ. Econ. 2019, 45, 75-85.

29. Davies, C.A.; Vandelanotte, C.; Duncan, M.J.; van Uffelen, J.G.Z. Associations of physical activity and screen-time on health related quality of life in adults. Prev. Med. 2012, 55, 46-49. [CrossRef] [PubMed]

30. Despres, J.-P. Physical activity, sedentary behaviours, and cardiovascular health: When will cardiorespiratory fitness become a vital sign? Can. J. Cardiol. 2016, 32, 505-513. [CrossRef] [PubMed]

31. Blümel, J.E.; Fica, J.; Chedraui, P.; Mezones-Holguín, E.; Zuñiga, M.C.; Witis, S.; Vallejo, M.S.; Tserotas, K.; Sánchez, H.; Onatra, W.; et al. Sedentary lifestyle in middle-aged women is associated with severe menopausal symptoms and obesity. Menopause 2016, 23, 488-493. [CrossRef]

32. Zheng, C. Study on the Influence of Fitness Behavior on Health-Related Quality of Life in Elderly with Chronic Diseases; Shandong University: Jinan, China, 2016.

33. Suchert, V.; Hanewinkel, R.; Isensee, B. Sedentary behavior and indicators of mental health in school-aged children and adolescents: A systematic review. Prev. Med. 2015, 76, 48-57. [CrossRef]

34. Wagner, A.L.; Keusch, F.; Yan, T.; Clarke, P.J. The impact of weather on summer and winter exercise behaviors. J. Sport Health Sci. 2019, 8, 39-45. [CrossRef] 
35. Sousa, A.G.; da Costa, T.H.M. Assessment of nutrient and food group intakes across sex, physical activity, and body mass index in an urban Brazilian population. Nutrients 2018, 10, 1741. [CrossRef]

36. Ma, G. Food, eating behavior, and culture in Chinese society. J. Ethn. Foods 2015, 2, 195-199. [CrossRef]

37. Qiushi, S. Chinese eat like this:15\% of people eat out every day. Policy Res. Explor. 2011, 23, $28-29$.

38. Xing, Y.; Li, S.; Yu, G. Catering Industry Blue Book: China's Catering Industry Development Report (2019); Social sciences academic press(CHINA): Beijing, China, 2019.

39. Michopoulou, E.; Jauniskis, P. Exploring the relationship between food and spirituality: A literature review. Int. J. Hosp. Manag. 2020, 87, 102494. [CrossRef]

40. Wansink, B.; Cheney, M.M.; Chan, N. Exploring comfort food preferences across age and gender. Physiol. Behav. 2003, 79, 739-747. [CrossRef]

41. Cruz, L.N.; Polanczyk, C.A.; Camey, S.A.; Hoffmann, J.F.; Fleck, M.P. Quality of life in Brazil: Normative values for the Whoqol-bref in a southern general population sample. Qual. Life Res. 2011, 20, 1123-1129. [CrossRef] [PubMed]

42. Ge, Y.; Xin, S.; Luan, D.; Zou, Z.; Gao, Q. Association of physical activity, sedentary time, and sleep duration on the health-related quality of life of college students in Northeast China. Health Qual. Life Outcomes 2019, 17, 124. [CrossRef] [PubMed]

43. Marzena, J.Z.; Jerzy, G.B.; Dominika, G.; Monika, W.T.; Dagmara, S.; Marta, P.; Milena, W. The Associations between dietary patterns and sedentary behaviors in Polish adults (LifeStyle Study). Nutrients 2018, 10, 1004.

44. Haskell, W.L.; Lee, I.M.; Pate, R.R.; Powell, K.E.; Blair, S.N.; Franklin, B.A.; Macera, C.A.; Heath, G.W.; Thompson, P.D.; Bauman, A. Physical activity and public health: Updated recommendation for adults from the American College of Sports Medicine and the American Heart Association. Med. Sci. Sports Exerc. 2007, 39, 1423-1434. [CrossRef]

45. O'Connell, S.E.; Griffiths, P.L.; Clemes, S.A. Seasonal variation in physical activity, sedentary behaviour and sleep in a sample of UK adults. Ann. Hum. Biol. 2014, 41, 1-8. [CrossRef]

46. Gavilán-Carrera, B.; Segura-Jiménez, V.; Estévez-López, F.; Álvarez-Gallardo, I.C.; Soriano-Maldonado, A.; Borges-Cosic, M.; Herrador-Colmenero, M.; Acosta-Manzano, P.; Delgado-Fernández, M. Association of objectively measured physical activity and sedentary time with health-related quality of life in women with fibromyalgia: The al-Ándalus project. J. Sport Health Sci. 2019, 8, 258-266. [CrossRef] 